Material Characterisation

\title{
Analysis and fate of the hindered amine light stabilizer Tinuvin 622 in polyester powder coatings using high performance liquid chromatography / time of flight mass spectrometry
}

\author{
Markus Wierer*, Wolfgang Buchberger, Christian W. Klampfl \\ Institute of Analytical Chemistry, Johannes Kepler University, Altenberger Strasse 69, 4040, Linz, Austria
}

\section{A R T I C L E I N F O}

\section{Keywords:}

Hindered amine light stabilizer

Polymer stabilization

Mass spectrometry

Powder coating

\begin{abstract}
A B S T R A C T
Hindered amine light stabilizers are used to protect polymers from heat- and light-induced degradation. In this study the oligomeric stabilizer Tinuvin 622 was analysed in-depth employing high performance liquid chromatography/time of flight mass spectrometry (HPLC/TOF-MS) to differentiate products of different manufacturers in respect of their terminating groups and oligomer length. Additionally, the behaviour of the stabilizer in uncured and cured polyester powder coatings was investigated regarding its interaction with the other coating components and chemical changes during the crosslinking process. The extraction efficiency was determined as a function of oligomer length and coating colour.
\end{abstract}

\section{Introduction}

Today, plastic materials are widely used within a wide range of industries. To comply with the requirements resulting from their utilization in a variety of different products (also meaning a large diversity of application fields), commercial plastics should be regarded as complex materials. In addition to various polymer molecules representing the backbone of the material, they include a substantial number of additives. The latter are crucial for giving the material its desired physical and chemical properties [1]. Within the group of polymer additives, stabilizers are an important subgroup, preventing the polymer from degradation caused by thermal, oxidative and UV-light induced stress [2]. For this purpose, a range of substances based on phenols, phosphites, benzotriazoles or hindered amine light stabilizers (HALS) has been developed. Particularly the latter are playing an increasingly important role, as they efficiently protect polymers against both heat and light induced degradation [3-5]. Within the group of HALS, two basically different types namely simple monomeric HALS and the more complex oligomeric HALS have to be distinguished. Focusing on HALS analysis, a series of possibilities for the simple and straightforward characterization and determination of monomeric HALS exists, which are not too different from the procedures described for other common polymer additives such as hindered phenol type or phosphite type stabilizers (for reviews see Ref. [6-9]). Analysis and characterization of oligomeric HALS, on the other hand, is affected with a series of obstacles [10-13]. One of the main reasons for the difficulties encountered in the analysis of these technical products are variations in the distribution of the oligomers, occurring in different batches (from one or different manufacturers) or induced by processing steps or aging [6,11-13]. Regarding the analysis and characterization of oligomeric HALS, such as Tinuvin 622 (Tin622, Fig. 1), based on the analytical question raised, different approaches can be followed. In some cases, the exact oligomer distribution is of less interest; instead a sum parameter allowing to determine the amount of each (oligomeric) HALS by combining as many structures as possible in a single signal is pursued [10]. If the oligomeric composition (and changes therein) or changes in the chemical nature of the end-groups is the target of interest, a thorough characterization of the different oligomers is compulsory. HPLC coupled to high resolution tandem mass spectrometry (HR MS/MS) $[11,13]$ or capillary electrophoresis coupled to HR MS/MS are the suitable tools [12,14].

HALS are also widely used in powder coatings. These are systems that are melted or chemically cured to give a closed coat on an object that serves protective and decorative purposes. Most powder coatings used today are chemically cured duroplastic systems based upon epoxy, polyester or acrylate resins cured with a variety of different crosslinkers. Depending on the resin component, (poly-)isocyanates, epoxycomponents or $\beta$-hydroxyl alkyl amides are used for this purpose next to a variety of other substances. The reaction types involved in the

\footnotetext{
* Corresponding author.

E-mail address: markus.wierer@jku.at (M. Wierer).
} 
curing process are either polyaddition reactions (epoxy- or isocyanatebased crosslinkers) or polycondensation reactions ( $\beta$-hydroxyl alkyl amides) [15]. Some of the described reactions can not only occur between resin and crosslinker, but also involve reactive groups in stabilizers [16]. Whereas possible interactions of coating components with the stabilizers are often evaluated on a macroscopic scale only (e.g. by measuring coating properties such as gloss in aging experiments) [17-19], there are only few reports where these phenomena are investigated on a molecular scale $[20,21]$.

In this paper we present an approach allowing the differentiation of batches (from one or multiple manufacturers) of Tin622 on the basis of an end-group analysis. Furthermore, the behaviour of this stabilizer in uncured and cured polyester powder coatings was investigated, particularly focusing on interactions with the other coating components and chemical changes during the crosslinking process.

\section{Experimental}

\subsection{Chemicals and materials}

Methanol, cyclohexane, dichloromethane, sulfuric acid, and toluene were purchased from VWR (Vienna, Austria). Ammonia solution 25\% (for analysis) was delivered by Merck (Darmstadt, Germany). Purified water was produced by a Milli-Q water purification system (Millipore, Bedford, MA, USA).

\subsection{Samples}

For method development ten different samples of Tin622 were provided by corporation partners and originated from three different manufacturers with the corresponding samples hereinafter referred to as Tin622_1-3, Tin622_4-9 and Tin622_10. The samples Tin622_2 and Tin622_10 are blends containing only $50 \%$ of Tin 622 next to another HALS. Tin622 solutions were prepared for all ten different samples in concentrations of $\beta(\operatorname{Tin} 622)=1000 \mathrm{mg} \mathrm{L}^{-1}$ in toluene and diluted to 20 $\mathrm{mg} \mathrm{L}^{-1}$ using methanol.

Nine samples of powder coatings each containing $0.5 \%$ of Tinuvin 622 were investigated. They were analysed as uncured powder and in form of a cured coating layer. The samples were provided by corporation partners and were based on acid-terminated pre-polymers and $N, N, N^{\prime}$, $N^{\prime}$-tetrakis(2-hydroxyethyl)adipamide as crosslinker. Three of those samples were coloured red $\left(\mathrm{Fe}_{2} \mathrm{O}_{3}\right.$ based pigment), three white $\left(\mathrm{TiO}_{2}\right.$ pigment) and the other three black (carbon black based pigment).

\subsection{Instrumentation}

Samples were chromatographically separated by reversed phase (RP)-HPLC using an Agilent 1260 HPLC system from Agilent Technologies (Waldbronn, Germany) equipped with a degasser, a quaternary pump, a diode-array UV-detector, and an auto sampler. As separation column a Triart C18 column $(50 \mathrm{~mm} \times 4.6 \mathrm{~mm}$, particle size $3.0 \mu \mathrm{m})$ from YMC (Kyoto, Japan) was used.

The general RP-HPLC separation method was based upon the literature [11] and modified to reduce the $\mathrm{NH}_{3}$ concentration in the mobile phase and the runtime. A tertiary water $/ \mathrm{MeOH} / \mathrm{cyclohexane}$ gradient was used with starting conditions set to $20 \%$ solvent A (water) and $80 \%$ solvent $\mathrm{B}$ ( $\mathrm{MeOH}$ with $0.03 \mathrm{~mol} \mathrm{~L}^{-1} \mathrm{NH}_{3}$ ). Until minute 20 solvent B was linearly increased to $100 \%$ and kept until minute 22 . From minute 22 to minute 60 solvent B was decreased to $75 \%$ while increasing solvent C (cyclohexane) to $25 \%$. Subsequently the gradient was changed back to $100 \%$ solvent $\mathrm{B}$ for $5 \mathrm{~min}$ and then to starting conditions. The re-equilibration conditions were held for $3 \mathrm{~min}$, resulting in a total runtime of $68 \mathrm{~min}$. The flow rate was set to $0.5 \mathrm{~mL} \mathrm{~min}^{-1}$, the column temperature was $40^{\circ} \mathrm{C}$. An injection volume of $20 \mu \mathrm{L}$ was selected for the $20 \mathrm{mgL}^{-1}$ solutions (comparison of products from different manufacturers), while $2 \mu \mathrm{L}$ were chosen for the higher concentrated $(\sim 100 \mathrm{mg}$ $\mathrm{L}^{-1}$ ) solutions extracted from coating samples.

For the characterization of the different oligomers the HPLC was coupled to an Agilent 6510 Q-TOF MS equipped with an ESI source. The QTOF system was operated in the positive ionization mode. The parameters were as follows: frame rate 1 frames $\mathrm{s}^{-1}$, capillary voltage $3750 \mathrm{~V}$, fragmentor voltage: $200 \mathrm{~V}$, drying gas flow rate $10 \mathrm{~L} \mathrm{~min}^{-1}$, drying gas temperature $350{ }^{\circ} \mathrm{C}$, nebulizer pressure $45 \mathrm{psi}$.

For the analysis of the coating samples an Agilent 1260 HPLC was hyphenated with an Agilent 6560 DTIM QTOF LC-MS equipped with a Dual AJS ESI ion-source (Agilent Technologies, Waldbronn, Germany)

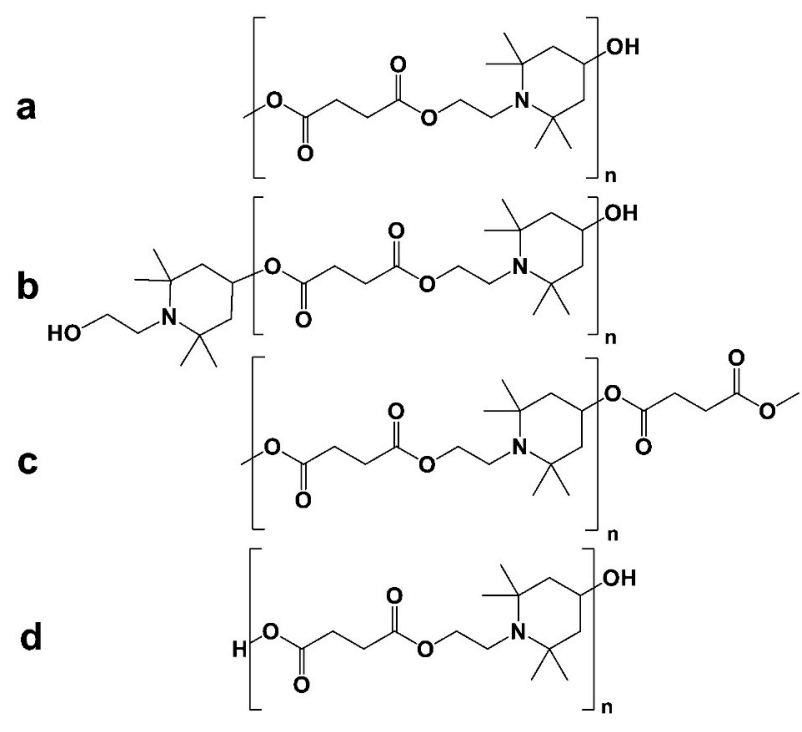

e<smiles>COC(=O)CCC(=O)OCCN1C(C)(C)C=C(OC(=O)CCC(=O)OC)CC1(C)C</smiles><smiles>CC(C)OC(=O)CCC(=O)OCCN1C(C)(C)CC(C)(OC(=O)CCC(=O)O)CC1(C)C</smiles><smiles>COC(=O)CCC(=O)OC1CC(C)(C)N(CCOC(=O)CCC(=O)OC2CC(C)(C)NC(C)(C)C2)C(C)(C)C1</smiles>

Fig. 1. Structure of Tinuvin 622 and its different termination options encountered throughout this study. a: mixed terminated $\left(\mathrm{HO}-\mathrm{XXX}^{-} \mathrm{COOCH}\right.$ ) b: $\mathrm{OH}-\mathrm{terminated}$ (HO-XXX-OH) c: methylester-terminated $\left(\mathrm{H}_{3} \mathrm{COOC}-\mathrm{XXX}-\mathrm{COOCH}_{3}\right) \mathrm{d}$ : mixed terminated lacking one $\mathrm{CH}_{3}$ group (HO-XXX-COOH) e: methylester-terminated lacking one $\mathrm{CH}_{3}$ group $\left(\mathrm{H}_{3} \mathrm{COOC}-\mathrm{XXX}-\mathrm{COOH}\right) \mathrm{f}$ : methylester-terminated lacking both $\mathrm{CH}_{3}$ groups $(\mathrm{HOOC}-\mathrm{XXX}-\mathrm{COOH}) \mathrm{g}$ : $\mathrm{OH}$ - terminated lacking one $\mathrm{CH}_{2} \mathrm{CH}_{2} \mathrm{OH}$ group $(\mathrm{HO}-$ $\mathrm{XXX}-\mathrm{NH}) \mathrm{h}$ : mixed terminated lacking one $\mathrm{CH}_{2} \mathrm{CH}_{2} \mathrm{OH}$ group $\left(\mathrm{H}_{3} \mathrm{COOC}-\mathrm{XXX}-\mathrm{NH}\right)$. 
as this instrument provided the better mass accuracy needed for an automated data analysis. The DTIM QTOF-MS was operated in the positive ionization mode with the following source parameters: drying gas temperature $350{ }^{\circ} \mathrm{C}$, drying gas flow rate $12 \mathrm{~L} \mathrm{~min}^{-1}$, nebulizer pressure $45 \mathrm{psi}$, sheath gas temperature $275^{\circ} \mathrm{C}$, sheath gas flow rate 12

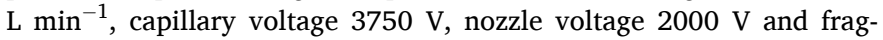
mentor voltage $350 \mathrm{~V}$. The ion mobility capability of the device was not used for oligomer analysis as a separation of differently charged ions of the same oligomer is unfavourable in data processing.

\subsection{Data processing}

The HPLC-TOF data were analysed using the Qualitative MS Browser B.10.00 software from Agilent in the "find by formula" mode and a list of reasonable sum-formulas of Tin622 oligomers with up to 35 repeating units and three different types of termination: OH-terminated (HO-XXX$\mathrm{OH})$, mixed terminated $\left(\mathrm{HO}-\mathrm{XXX}-\mathrm{COOCH}_{3}\right)$ and methylester-terminated $\left(\mathrm{H}_{3} \mathrm{COOC}-\mathrm{XXX}-\mathrm{COOCH}_{3}\right)$. The allowed charge states were set to $z=+1$ to $z=+10$. The results were used to determine the retention times of each of the Tinuvin 622 oligomers. The results of twenty measured samples were manually checked for plausibility and the retention time of each oligomer was averaged and used to create a database for further use. In the case that samples contain previously unknown types of Tin622 oligomers, those were added to the list and all other samples were checked for their presence. A list of all detected oligomers and their retention times is given in the supporting information.

\section{Results and discussion}

\subsection{Determination of the Tin622 composition of different Tinuvin 622} batches using HPLC-TOF

Tin622 is the polycondensation product of dimethyl succinate and 1(2-hydroxyethyl)-2,2,6,6-tetramethylpiperidine-4-ol. Depending on the reaction parameters different oligomers may be dominant in the final product. An excess of diol leads to a higher proportion of $\mathrm{HO}-\mathrm{XXX}-\mathrm{OH}$ type oligomers whereas a surplus of dimethyl succinate statistically favours $\mathrm{H}_{3} \mathrm{COOC}-\mathrm{XXX}-\mathrm{COOCH}_{3}$ type oligomers. The composition of Tin622 with respect to oligomer chain length and terminating groups and changes therein can be a relevant parameter in industrial applications and in artificial aging experiments.

Using the described HPLC gradient the smallest oligomers elute at the lowest retention times starting with 1-(2-hydroxyethyl)-2,2,6,6-tetramethylpiperidine-4-ol at $1.30 \mathrm{~min}$. The largest detected oligomers contain 25 repeating units and elute $43 \mathrm{~min}$ after injection. Looking at an exemplary chromatogram for Tin622_9 shown in Fig. 2, it is clearly visible that the $\mathrm{OH}$-terminated and mixed terminated oligomers dominate the chromatogram. Integrating the peaks, adding up areas for the differently terminated oligomeric series and dividing by the sum of all peak areas gives relative abundances for each of these series. This relative abundance is related to parameters in the production process of the individual Tin622 batch like the ratio of 1-(2-hydroxyethyl)-2,2,6,6tetramethylpiperidine-4-ol to dimethyl succinate.

Next to the known main constituents of Tin622 [11] shown in Fig. 1 (a-c) differently terminated oligomers were found lacking either one or two terminal methyl groups as shown in Fig. 1(d-f). Those oligomers were especially numerous in the sample Tin622_2 for reasons unknown. The assumption that the missing methyl group is terminal is based upon the retention times differing significantly from the corresponding oligomers not missing the $\mathrm{CH}_{3}$ group (see Fig. S1). If the missing methyl group was e.g. one of the methyl groups in the 1-(2-hydroxyethyl)-2,2,6, 6 -tetramethylpiperidine-4-ol groups, the change in retention time would only be minor. This is additionally confirmed by the fact that oligomers missing a $\mathrm{CH}_{3}$ group are not found in $\mathrm{HO}-\mathrm{XXX}-\mathrm{OH}$ type oligomers as they do not contain terminal $\mathrm{CH}_{3}$ groups. Using this methodology, the available samples can be characterized and compared. This comparison is shown in Fig. 3. Differences between the samples concerning the terminating groups are substantial, with abundances of methylester-terminated oligomers ranging from $2.7 \%$ to $18.7 \%$ and the $\mathrm{OH}$-terminated oligomers from $33.2 \%$ to $68.5 \%$. The variations within

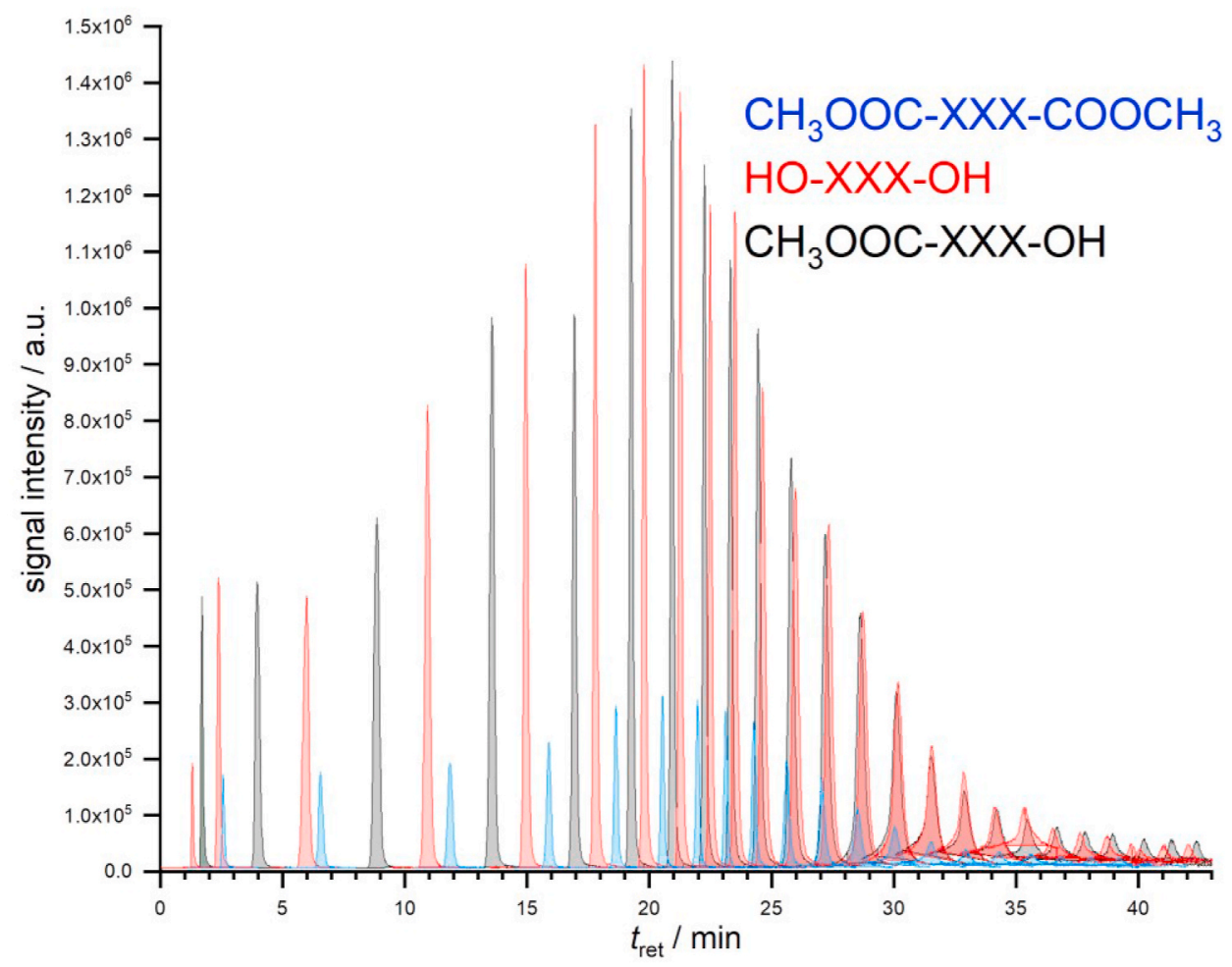

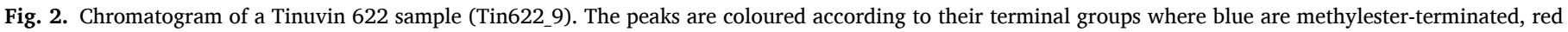
are $\mathrm{OH}$-terminated and black are mixed terminated oligomers. 


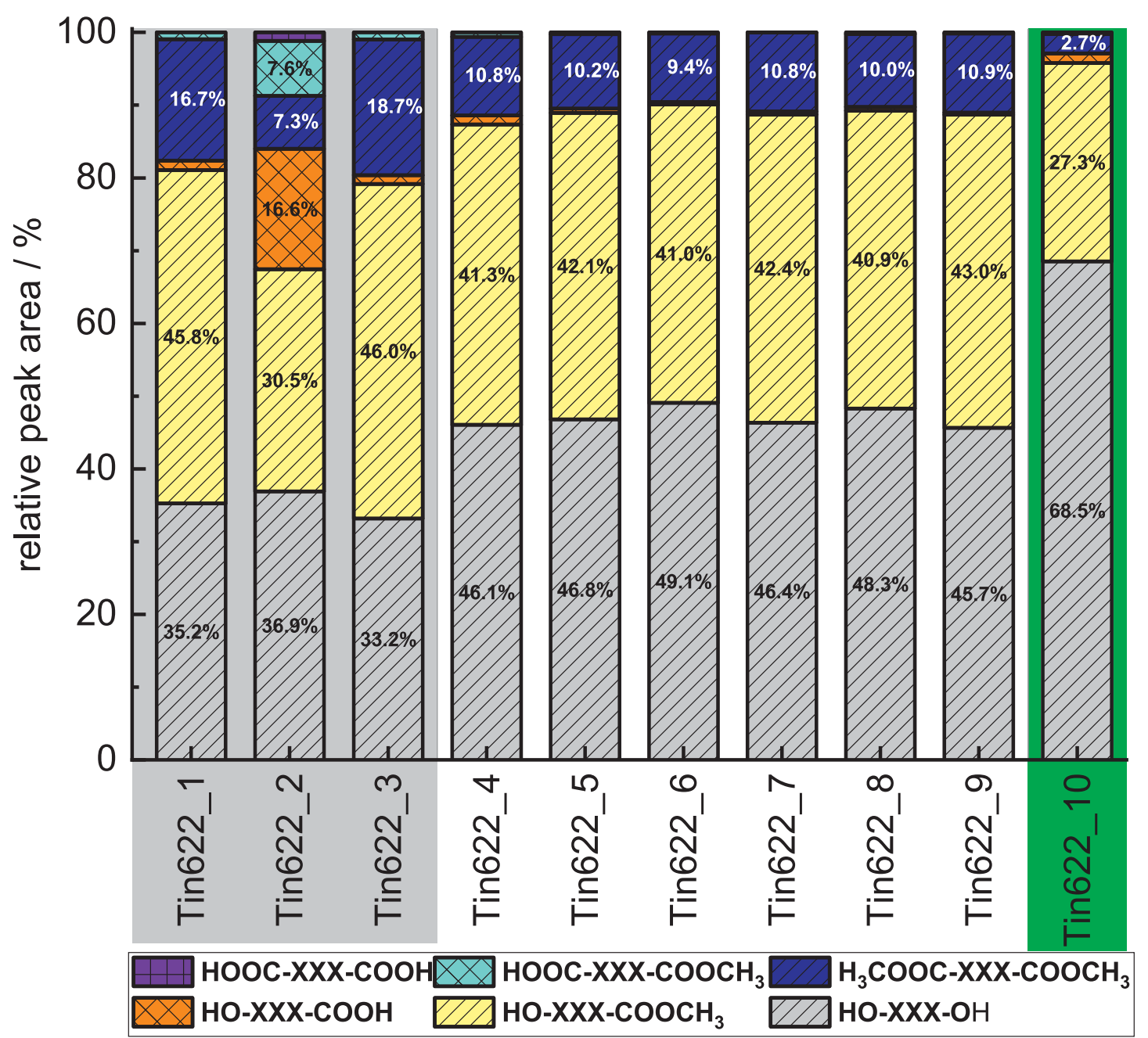

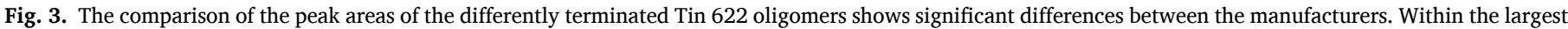
group (Tin622_4 to Tin622_9) the differences between the samples are only minor.

samples of the same manufacturer are comparably small with abundances of methylester-terminated oligomers ranging from $9.6 \%$ to $11.5 \%$ and the OH-terminated oligomers from $45.5 \%$ to $49.0 \%$ within the largest group containing six samples (Tin622_4 - Tin622_9).

The sample Tin622_10 is noteworthy because it severely differs from the other samples as it contains the highest abundance of $\mathrm{OH}$-terminated and the smallest amount of methylester-terminated oligomers suggesting that in the production process a higher excess of diol was used in contrast to the samples of the other manufacturers. This can also be seen when comparing the average measured oligomer length as summarized in Fig. S2 where the Tin622_10 sample shows shorter chain lengths than the other samples. These findings correspond to a situation when one of the polycondensation educts is in excess during production.

\subsection{Analysis of Tinuvin 622 in uncured polyester coatings}

To proof the viability of the developed method in real samples, the composition of Tin622 oligomers in uncured polyester powder coating samples containing $0.5 \%$ of a commercially product from the same manufacturer as the samples Tin622_4 - Tin622_9 was measured. $10 \mathrm{mg}$ of each sample were dissolved/extracted using $300 \mu \mathrm{L}$ of dichloromethane (DCM) for $30 \mathrm{~min}$ in an ultrasonic bath at room temperature. The DCM solution was then again extracted using $1 \mathrm{~mL}$ of $0.01 \mathrm{~mol} \mathrm{~L}^{-1}$ aqueous $\mathrm{H}_{2} \mathrm{SO}_{4}$ to separate Tin622 from most other coating components. The resulting solutions of Tin 622 oligomers in $0.01 \mathrm{~mol} \mathrm{~L}^{-1} \mathrm{H}_{2} \mathrm{SO}_{4}$ were measured using the HPLC-TOF method described above.
The results for the abundances of differently terminated oligomers are shown in Table 1 and Fig. S3. The uncertainty is given as standard deviation of 27 measurements. The distribution of terminations is similar to the samples Tin622_4 - Tin622_9 originating from the same manufacturer, although containing more oligomers lacking their terminal methyl group (HO-XXX-COOH and $\mathrm{CH}_{3} \mathrm{OOC}-\mathrm{XXX}-\mathrm{COOH}$ type). Oligomers of the type HOOC-XXX-COOH, lacking both terminal $\mathrm{CH}_{3}$ groups, were found in all 27 analysed samples but their low abundances complicate peak identification and therefore reliable quantitation.

As the sample preparation includes the extraction using $0.01 \mathrm{~mol}$ $\mathrm{L}^{-1} \mathrm{H}_{2} \mathrm{SO}_{4}$, the comparably high abundance of $\mathrm{COOH}$-terminated oligomers could be suspected to originate from the hydrolysis of terminal methyl groups in the acidic environment. To control for this effect the

Table 1

Relative peak areas and standard deviations of all different Tin622 oligomers found in 9 different samples of uncured polyester powder coating. Each sample was analysed 3 times.

\begin{tabular}{lll}
\hline Oligomer type & Relative peak area/\% & Standard deviation $(\mathrm{n}=27) / \%$ \\
\hline HO-XXX-OH & 52.18 & 0.48 \\
$\mathrm{H}_{3} \mathrm{C}-\mathrm{OOC}-\mathrm{XXX}-\mathrm{OH}$ & 36.16 & 0.29 \\
HOOC-XXX-OH & 1.49 & 0.06 \\
$\mathrm{H}_{3} \mathrm{C}-\mathrm{OOC}-\mathrm{XXX}-$ & 6.18 & 0.14 \\
$\quad \mathrm{COOCH}_{3}$ & & \\
$\mathrm{H}_{3} \mathrm{COOC}-\mathrm{XXX}-\mathrm{COOH}$ & 3.49 & 0.08 \\
HOOC-XXX-COOH & 0.07 & 0.07 \\
\hline
\end{tabular}


results for the relative abundance of the differently terminated oligomers were plotted against the time between $\mathrm{H}_{2} \mathrm{SO}_{4}$ addition and injection into the HPLC-MS (Fig. S4). No relevant change in composition was found over a period of $32 \mathrm{~h}$. This means that the $\mathrm{H}_{2} \mathrm{SO}_{4}$ extraction does not influence the termination of Tin622 oligomers. The measured abundances of $\mathrm{COOH}$-terminated oligomers are therefore actually present in the coatings and not an artefact originating from sample preparation.

\subsection{Analysis of Tinuvin 622 in cured polyester coatings}

The curing of the analysed coating type involves an esterification reaction between the pre-polymers $\mathrm{COOH}$ groups with the crosslinkers OH groups as depicted in Fig. 4 [15]. As most of the Tin622 oligomers found in chapter 3.1 and 3.2 are at least partly $\mathrm{OH}_{-}$or $\mathrm{COOH}$-terminated, it is to expect that during the process of curing those oligomers are at least in part covalently bound to the polymer backbone. Reactions between $\mathrm{OH}$-terminated and $\mathrm{COOH}$-terminated Tin622 oligomers can theoretically also occur, although this is highly unlikely due to the low concentration of Tin622 compared to the other $\mathrm{COOH}$ - or $\mathrm{OH}$-containing coating ingredients. To investigate the behaviour of Tin622 in cured coatings the same sample preparation procedure as for the uncured samples is used. It is notable that contrary to the uncured samples they are no longer mostly dissolved but just swollen by the DCM, as the polyester backbone is crosslinked and therefore insoluble without breaking covalent bonds. This brings the additional complication, that it is no longer clear if all the different oligomer lengths of Tin622 are extracted to the same degree, independent of length and termination.

23 measurements of the cured coatings were conducted whereby the red and white coatings were analysed nine times and the black coating five times. The results for the main terminations $(>5 \%$ relative peak area) are given in Fig. 5 while the minor terminations $(<5 \%$ relative peak area) are given separately in Fig. 6.

For all oligomers with the various terminations a significant change in their relative abundance was visible $(\mathrm{P}=95 \%)$ in white and red coatings. In the black coating the changes in relative abundance for HO$\mathrm{XXX}-\mathrm{COOH}$ and $\mathrm{HOOC}-\mathrm{XXX}-\mathrm{COOCH}_{3}$ oligomers were not statistically significant $(\mathrm{P}=95 \%)$. In the white and red coatings the oligomers with terminal HOOC groups are significantly reduced most likely due to bonding to the crosslinkers $\mathrm{OH}$ groups.

In addition to the already known terminations, Tin622 oligomers lacking terminal $\mathrm{CH}_{2} \mathrm{CH}_{2} \mathrm{OH}$ groups (as depicted in Fig. $1 \mathrm{~g}$-h) were found in the cured samples. These oligomers were not present in the

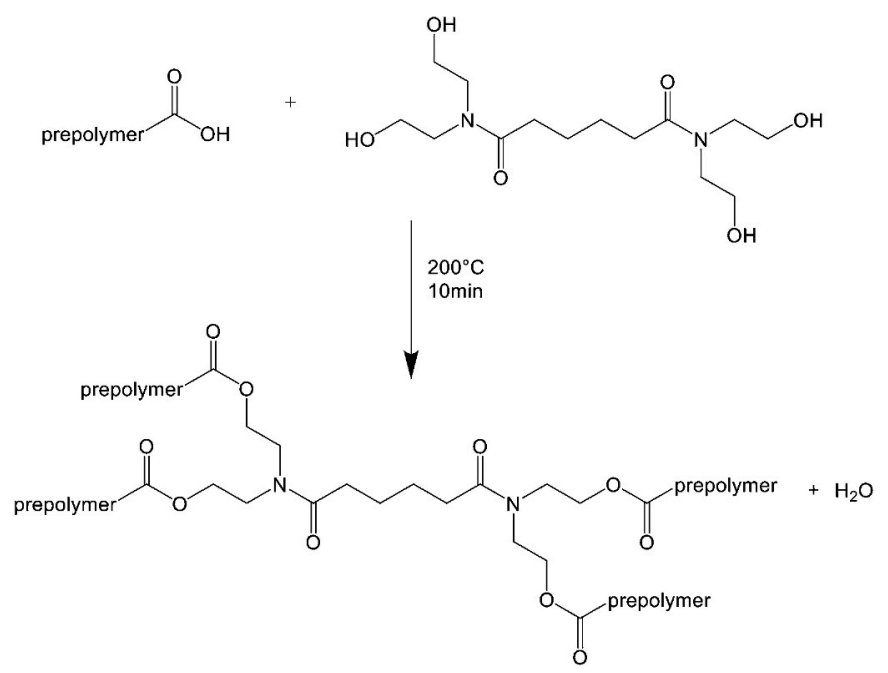

Fig. 4. Crosslinking of acid-terminated polyester pre-polymers with $\mathrm{N}, \mathrm{N}, \mathrm{N}^{\prime}, \mathrm{N}^{\prime}$ tetrakis(2-hydroxyethyl)adipamide [15]. uncured samples which suggests that they are created during the heat treatment of the curing process most likely while they act as antioxidants via the Denisov cycle [22].

Next to the changes in detected terminations, also the average detected length of Tin622 oligomers significantly decreased from an average length of 10.7 1-(2-hydroxyethyl)-2,2,6,6-tetramethylpiperidyl groups in uncured samples to only around nine repeating units in cured coatings (red: 8.9, white: 9.4 black 8.3). This may be explained by either partial splitting of the Tin622 chains during the curing of the coating or by a size dependent extraction efficiency of Tin622 oligomers when extracting from the cured coating.

To distinguish between those two cases the extraction efficiency for each of the main Tin622 oligomers (HO-XXX-OH, HO-XXX-COOCH 3 and $\mathrm{H}_{3} \mathrm{COOC}-\mathrm{XXX}-\mathrm{COOCH}_{3}$ ) was calculated separately. It was found that, next to the oligomer's length, the used pigment has a significant influence on the extraction efficiency. This is depicted in Fig. S5 where the extraction efficiency is plotted against the length (=number of 1-(2hydroxyethyl)-2,2,6,6-tetramethylpiperidyl groups) of the individual Tin622 oligomer. The relationship between extraction efficiency and oligomer length can generally be described as a linear relationship. For small oligomers (less than five 1-(2-hydroxyethyl)-2,2,6,6-tetramethylpiperidyl groups) this relationship does not hold true, most likely because other effects than oligomer length are influencing the extraction. At higher oligomer lengths of $>25$ 1-(2-hydroxyethyl)-2,2,6,6tetramethylpiperidyl groups the linear relationship also fails, caused by the unreliability of the peak identification and quantitation. Adding the information on the terminating groups to the plot reveals clear differences in the extraction efficiencies between the different types of oligomers (Fig. S6). Methylester-terminated oligomers show the highest extraction efficiencies followed by mixed terminated and $\mathrm{OH}$ terminated oligomers. This would suggest either a covalent bonding of the terminal $\mathrm{OH}$ groups in $\mathrm{H}_{3} \mathrm{COOC}-\mathrm{XXX}-\mathrm{OH}$ and $\mathrm{HO}-\mathrm{XXX}-\mathrm{OH}$ type oligomers to the polymer backbone or a splitting of Tin622 oligomers. But these interpretations ignore the Tin622 oligomers lacking their terminal $-\mathrm{CH}_{2} \mathrm{CH}_{2} \mathrm{OH}$ group (HO-XXX-NH and $\mathrm{H}_{3} \mathrm{COOC}-\mathrm{XXX}-\mathrm{NH}$ type oligomers). If the extraction efficiency for each $\mathrm{HO}-\mathrm{XX}-\mathrm{OH}$ type oligomer is corrected for the corresponding HO-XXX-NH oligomer and each $\mathrm{H}_{3} \mathrm{COOC}-\mathrm{XXX}-\mathrm{OH}$ oligomer for its $\mathrm{H}_{3} \mathrm{COOC}-\mathrm{XXX}-\mathrm{NH}$ species the differences in extraction efficiencies between the differently terminated oligomers vanish (Fig. 7+ S7). This suggests that there is neither significant splitting of Tin622 chains nor covalent bonding between the hydroxyl groups to the polymer backbone. This is especially noteworthy as these oligomers possess end groups similar to those of the crosslinker used.

\section{Conclusion}

The described method is a useful tool to investigate the structural differences of Tinuvin 622 originating from different manufacturers and its chemical behaviour in crosslinked coatings. It could be shown that the stabilizers sold as Tinuvin 622 or under a similar label can differ significantly between manufacturers. This can be best seen when comparing the relative abundances of differently terminated oligomers.

Applying a slightly modified sample preparation method to the analysis of Tin622 in polyester powder coatings and their crosslinking process reveals the different behaviour of the differently terminated Tin622 oligomers. $\mathrm{COOH}$ terminated oligomers can react with the crosslinker present in the investigated coatings, while $\mathrm{OH}$ terminated oligomers can lose their terminal $\mathrm{CH}_{2} \mathrm{CH}_{2} \mathrm{OH}$ group, possibly via the Denisov cycle. Reactions between the $\mathrm{OH}$-terminated Tin622 oligomers and $\mathrm{COOH}$ terminated polyester prepolymers were not observed although the terminal OH groups of Tin622 are chemically similar to those of the used $\beta$-hydroxyalkylamide crosslinker used for curing.

The extraction efficiency was determined for approximately hundred different Tin622 oligomers present in the cured coating samples. After applying corrections for changes in the chemical structure of the 


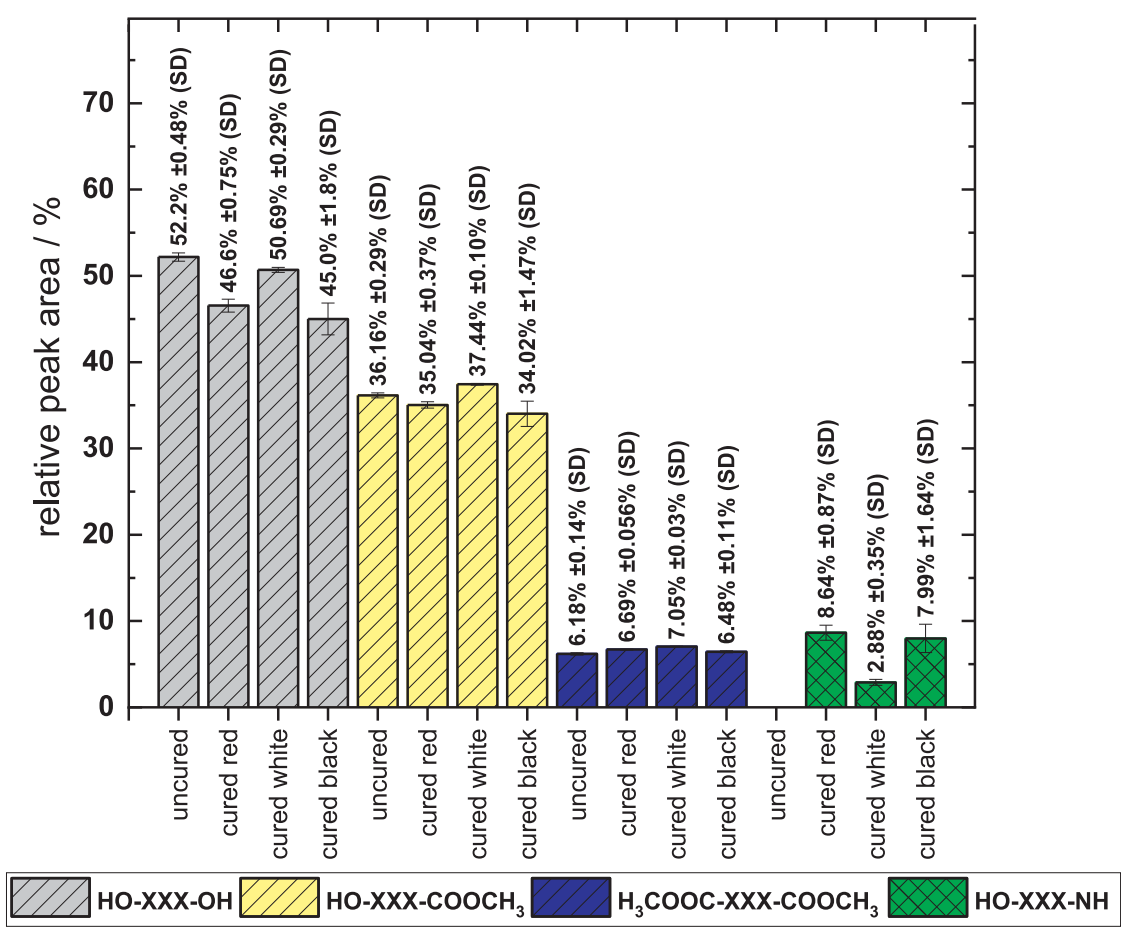

Fig. 5. Changes in the major Tin622 oligomers abundances due to the crosslinking reaction. The HO-XXX-NH terminated oligomers are created during the crosslinking process.

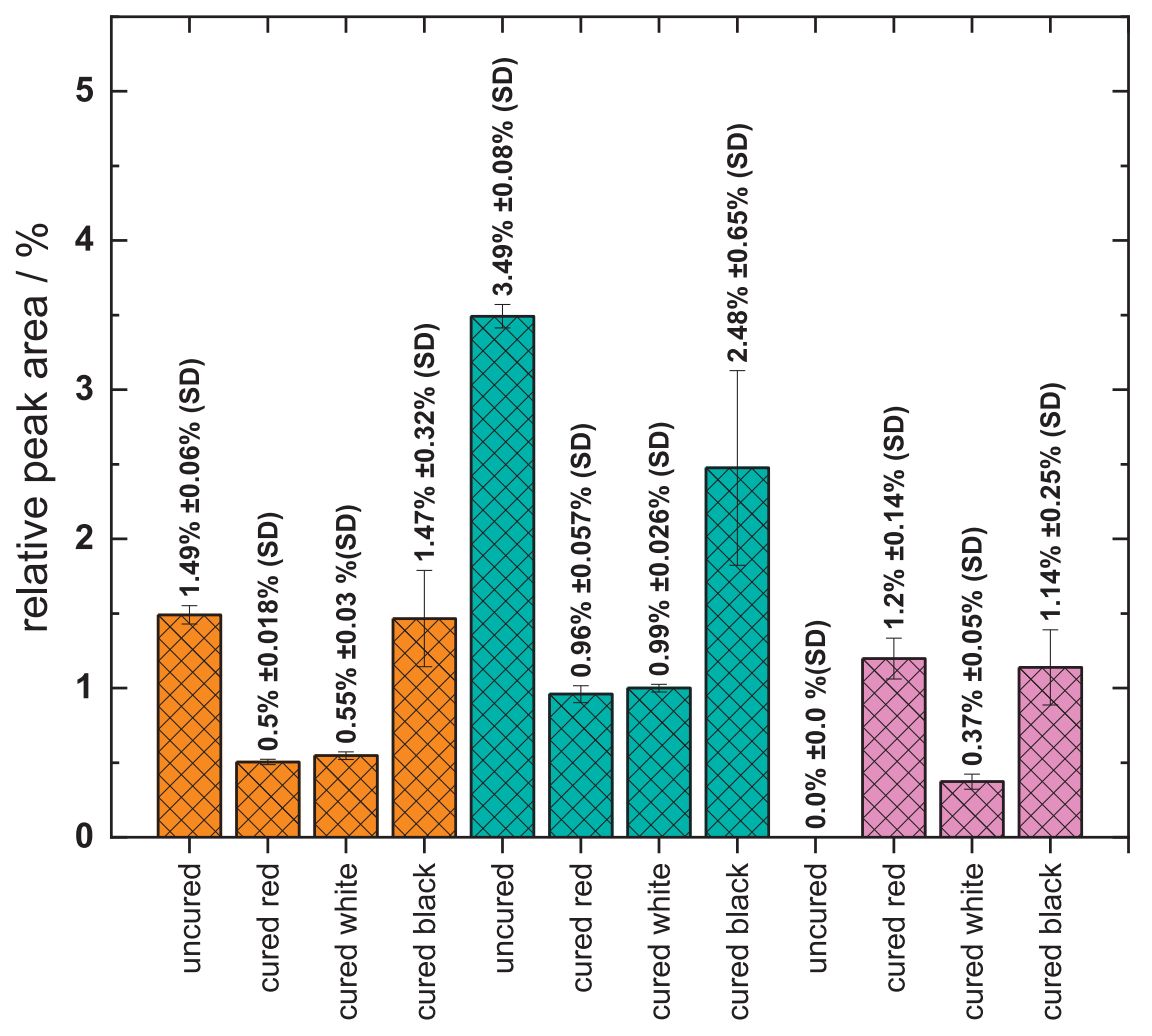

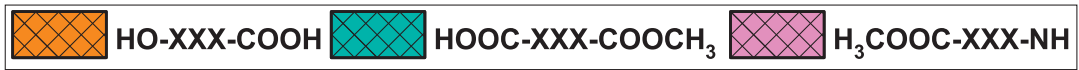

Fig. 6. Changes in the minor Tin622 oligomers abundances due to the crosslinking reaction. The abundance of COOH-terminated oligomers is decreased due to reaction with the crosslinker. $\mathrm{H}_{3} \mathrm{COOC}-\mathrm{XXX}-\mathrm{NH}$ type oligomers are created during the crosslinking process. 


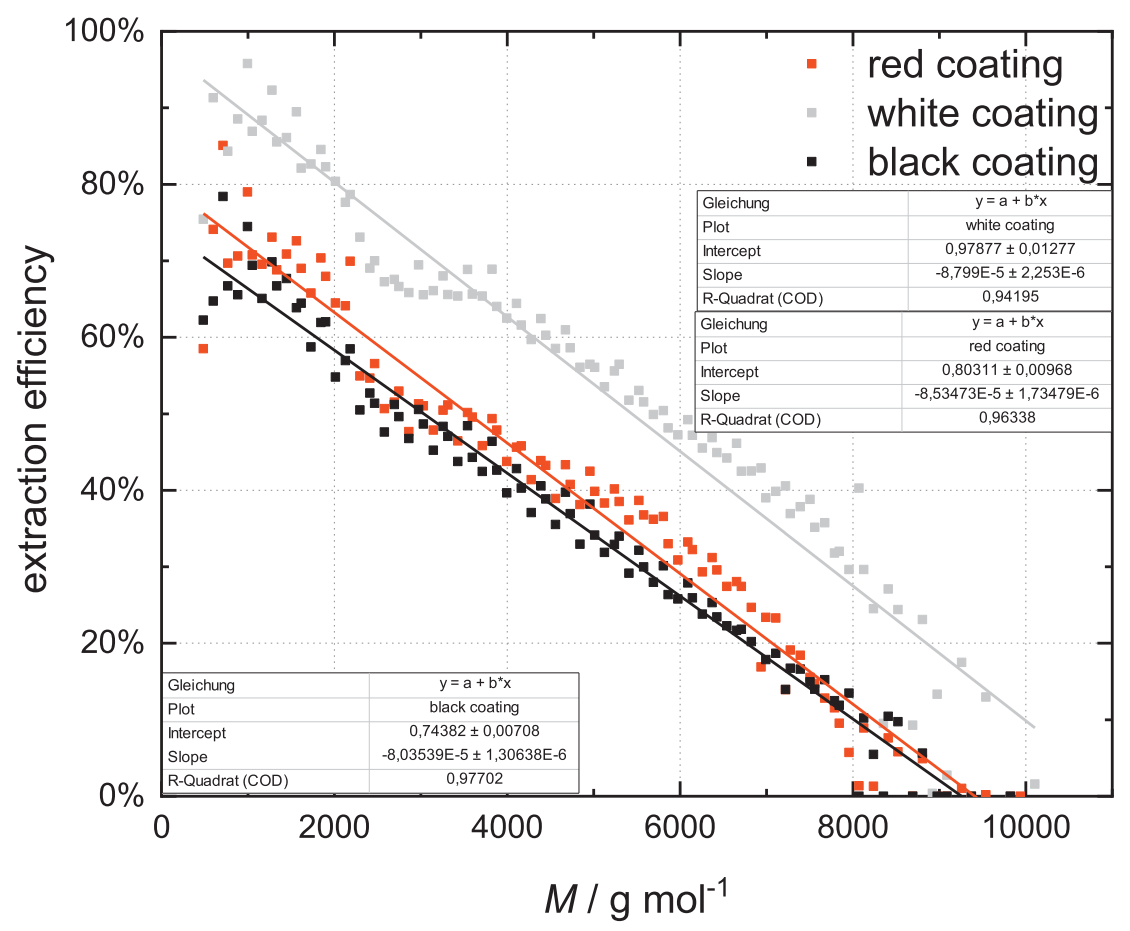

Fig. 7. Linear relationship between extraction efficiency and molecular mass after correcting for the Tin622 oligomers losing their terminal $\mathrm{CH}_{2} \mathrm{CH}_{2} \mathrm{OH}$ groups.

stabilizers (e.g. loss of $\mathrm{CH}_{2} \mathrm{CH}_{2} \mathrm{OH}$ group) a mostly linear correlation between molecular mass and extraction efficiency was found suggesting that Tin622 oligomers being only $\mathrm{OH}$ or methylester terminated are not chemically bound during crosslinking.

The analysis of Tin622 might also be used as a tool to systematically investigate the influence of different groups present in other coating additives on their tendency to chemically bond to the backbone as it possesses several different terminating groups that can be investigated in one go. Further work involving different prepolymer/crosslinker systems is needed to fully understand the interactions between stabilizers and coating during the crosslinking process.

\section{Data availability}

The raw/processed data required to reproduce these findings cannot be shared at this time due to technical or time limitations.

\section{Declaration of competing interest}

The authors declare that they have no known competing financial interests or personal relationships that could have appeared to influence the work reported in this paper.

\section{CRediT authorship contribution statement}

Markus Wierer: Conceptualization, Methodology, Investigation, Writing - original draft. Wolfgang Buchberger: Resources, Writing review \& editing, Supervision, Funding acquisition. Christian W. Klampfl: Writing - review \& editing, Supervision, Project administration.

\section{Acknowledgements}

Part of this work was supported by the Austrian Research Promotion Agency (FFG) project 858569 (STABILACK).

\section{Appendix A. Supplementary data}

Supplementary data to this article can be found online at https://doi. org/10.1016/j.polymertesting.2020.106677.

\section{References}

[1] D.R. Jenke, Organic polymer additives: identification and quantification, in: Encyclopedia of Chromatography, third ed., CRC Press, Bocca Raton, 2010.

[2] H. Zweifel, Plastic Additives Handbook, fifth ed., Hanser, Munich, 2000.

[3] Y. Ohkatsu, Search for unified action mechanism of hindered amine light stabilizers, J. Jpn. Petrol. Inst. 51 (2008) 191-204.

[4] M.R.L. Paine, P.J. Barker, S.J. Blanksby, Desorption Electrospray ionisation mass spectrometry reveals in situ modification of a hindered amine light stabiliser resulting from direct N-OR bond cleavage, Analyst 136 (2011) 904-912.

[5] J.L. Hodgson, M.L. Coote, Clarifying the mechanism of the Denisov cycle: how do hindered amine light stabilizers protect polymer coatings from photo-oxidative degradation? Macromolecules 43 (2010) 4573-4583.

[6] C.W. Klampfl, M. Himmelsbach, Advances in the analysis of hindered amine light stabilizers: a Review, Anal. Chim. Acta 933 (2016) 10-22.

[7] C.W. Klampfl, Mass spectrometry as a useful tool for the analysis of stabilizers in polymer materials, Trac. Trends Anal. Chem. 50 (2013) 53.

[8] H.G. Barth, R.E. Majors, Approaches for extracting and determining additives, contaminants and low-molecular-weight by-products in synthetic polymers, LC GC 26 (2013) 23-33.

[9] W. Buchberger, M. Stiftinger, Analysis of polymer additives and impurities by liquid chromatography/mass spectrometry and capillary electrophoresis/mass spectrometry, in: M. Hakkarainen (Ed.), Mass Spectrometry of Polymers-New Techniques, Springer, Heidelberg, 2012.

[10] G. Kreisberger, W.W. Buchberger, Rapid determination of oligomeric hindered amine light stabilizers in polymeric materials, J. Separ. Sci. 40 (2017) 2366-2373.

[11] I. Hintersteiner, M. Reisinger, M. Himmelsbach, W. Buchberger, Wolfgang Separation and characterization of oligomeric hindered amine light stabilizers using high-performance liquid chromatography with UV and quadrupole time-offlight mass spectrometric detection, J. Separ. Sci. 39 (2016) 1056-1066.

[12] I. Hintersteiner, T. Schmid, M. Himmelsbach, C.W. Klampfl, W.W. Buchberger, Quantitative analysis of hindered amine light stabilizers by CZE with UV detection and quadrupole TOF mass spectrometric detection, Electrophoresis 35 (2014) 2965-2971.

[13] M. Reisinger, S. Beissmann, W. Buchberger, Quantitation of hindered amine light stabilizers in plastic materials by high performance liquid chromatography and mass spectrometric detection using electrospray ionization and atmospheric pressure photoionization, Anal. Chim. Acta 803 (2013) 181-187.

[14] I. Hintersteiner, M. Himmelsbach, C.W. Klampfl, W.W. Buchberger, Characterization of hindered amine light stabilizers employing capillary electrophoresis coupled to quadrupole time-of-flight mass spectrometry, Electrophoresis 35 (2014) 1368-1374. 
[15] J. Pietschmann, Industrielle Pulverbeschichtung, 3, Vieweg+Teubner, Berlin, 2010.

[16] BASF Corporation, "Technical Data Sheet Tinuvin $®$ 152", 2016. October.

[17] A. Valet, A. Braig, Light Stabilizers for Coatings, second ed., Vincentz Network, Hanover, 2017.

[18] C. Schaller, D. Rogez, A. Braig, Hindered amine light stabilizers in pigmented coatings, J. Coating Technol. Res. 6 (2009) 81-88.

[19] S. Zeren, UV stabilisation of powder clear coats, Macromol. Symp. 187 (2002) 343-356.
[20] J.L. Gerlock, A.V. Kucherov, C.A. Smith, Determination of active HALS in automotive paint systems II: HALS distribution in weathered clearcoat/basecoat paint systems, Polym. Degrad. Stabil. 73 (2001) 201-210.

[21] I. Park, K.H. Yoon, H. Namgoong, Determination of Tinuvin 292 in acrylic resins by reversed-phase high-performance liquid chromatography-electrospray ionization-ion trap mass spectrometry, Chem. Lett. 41 (2012) 301-303.

[22] Y.B. Shilov, Y.T. Denisov, Mechanism of the inhibiting action of the iminoxyl radical during the oxidation of polypropylene and polyethylene, Polym. Sci. USSR 16 (1974) 2686-2690. 